\title{
Is miniscrew primary stability influenced by bone density?
}

\section{Mariana Marquezan ${ }^{(a)}$ Margareth Maria Gomes de Souza ${ }^{(a)}$ \\ Mônica Tirre de Souza Araújo(a) \\ Lincoln Issamu Nojima(a) Matilde da Cunha Gonçalves Nojima(a)}

(a) Pedodontics and Orthodontics Department, Federal University of Rio de Janeiro (UFRJ), Rio de Janeiro, RJ, Brazil.
Declaration of Interests: The authors certify that they have no commercial or associative interest that represents a conflict of interest in connection with the manuscript.

\section{Corresponding author:}

Matilde da Cunha Gonçalves Nojima

E-mail: matildenojima@uol.com.br

Received for publication on May 24, 2011 Accepted for publication on Jul 20, 2011
Abstract: Primary stability is absence of mobility in the bone bed after mini-implant placement and depends on bone quality among other factors. Bone quality is a subjective term frequently considered as bone density. The aim of this preliminary study was to evaluate bone density in two bovine pelvic regions and verify the primary stability of miniscrews inserted into them. Forty bone blocks were extracted from bovine pelvic bones, 20 from iliac and 20 from pubic bone, all of them containing cortical bone about $1 \mathrm{~mm}$ thick. Half of the sections extracted from each bone were designated for histological evaluation of bone density (trabecular bone area - TBA) and the other half for bone mineral density (BMD) evaluation by means of central dual-energy X-ray absorptiometry (DEXA). Then, twenty self-drilling miniscrews (INP ${ }^{\circledR}$, São Paulo, Brazil) $1.4 \mathrm{~mm}$ in diameter and $6 \mathrm{~mm}$ long were inserted into the bone blocks used for BMD evaluation. Peak implant insertion torque (IT) and pullout strength (PS) were used for primary stability evaluation. It was found that iliac and pubic bones present different bone densities, iliac bone being less dense considering BMD and TBA values $(\mathrm{P}>0.05)$. However, the miniscrew primary stability was not different when varying the bone type $(\mathrm{P}<0.05)$. IT and PS were not influenced by these differences in bone density when cortical thickness was about $1 \mathrm{~mm}$ thick.

Descriptors: Bone and Bones; Bone Density; Orthodontic Anchorage Procedures.

\section{Introduction}

Primary stability is absence of mobility in the bone bed after implant or mini-implant placement. ${ }^{1,2}$ It is achieved by mechanical contact between the miniscrew surface and bone ${ }^{3}$ and depends on the characteristics of devices ${ }^{4,5}$, insertion technique ${ }^{4}$ and bone quality and quantity of the receptor site..$^{4,6-8}$

The primary stability plays an important role in the successful secondary stability of miniscrews, since lack of immediate stability can lead to progressive mobility of the device and its subsequent loss. ${ }^{9}$ In clinical use, the initial stability of miniscrews is also considered essential, because of immediate or early load applied on them in many patients. ${ }^{10}$ It has been suggested that if initial mechanical retention of the mini-implant is not observed, it should be replaced by a thicker device, or its insertion site should be changed. ${ }^{11}$ Primary stability has traditionally been assessed by the practitioner through manual verification. ${ }^{12}$ Several other less subjec- 
tive methods are described in the literature: histological (BIC - bone to implant contact), which assesses the percentage of bone to implant contact; mechanical, which assesses insertion and removal torque or pullout strength of mini-implants, and the percussion method (Periotest value). However, there is still no gold standard to assess the primary stability of miniscrews. ${ }^{13}$

The term "bone quality" is not clearly defined in the literature. This includes physiological and structural aspects and degree of bone tissue mineralization. ${ }^{14}$ Aspects such as bone metabolism, cell turnover, maturation, intracellular matrix and vascularity have also been emphasized. ${ }^{1}$ Nevertheless, the role of each of these aspects is not completely understood. ${ }^{14}$ In Implant dentistry, the most accepted classification of bone quality has been the one proposed by Lekholm and Zarb. ${ }^{15}$ This was based on the amount of cortical and trabecular bone shown in preoperative radiographs. This classification, however, depends on the operator's subjectivity during radiographic evaluation.

A less subjective method for evaluating cortical and trabecular bone quality is to verify bone mineral density (BMD). ${ }^{14}$ Bone densitometry is taken as the gold standard for quantifying BMD in Endocrinolo- gy and Traumatology. ${ }^{16}$ The bone mineral content of tissue is measured and divided by the area of tissue to obtain bone mineral density. Another parameter of bone quality evaluated in implant dentistry is trabecular bone density. For this measurement, however, the percentage of trabecular bone area in the total biopsy area is calculated. The trabecular bone area (TBA) instead of mineral content is evaluated. For TBA analysis, histological and morphometrical methods are considered the gold standard. ${ }^{1}$

Considering the above, the aim of this study was to evaluate the primary stability of miniscrews inserted in two bovine pelvic regions with different densities, to verify the influence of bone density on stability.

\section{Methodology}

The sample comprised 40 bone sections extracted from bovine pelvis (Bos taurus), Angus lineage. Ten pelvic bones were obtained from a Slaughterhouse (registered with ANVISA - the Brazilian Health Surveillance Agency) immediately after slaughter. From each bone, two small bone sections were taken from the gluteal wing of the iliac and from the pubic bone (Figure 1). Tissue sections were removed by means of a trephine bur $(8 \mathrm{~mm}$ in diam-
Figure 1 - Macroscopic view of the right hemi pelvis. (a) caudal view: the arrow indicates the gluteal wing of the iliac bone. (b) medial view: the arrow indicates the caudal portion of the pubic bone.
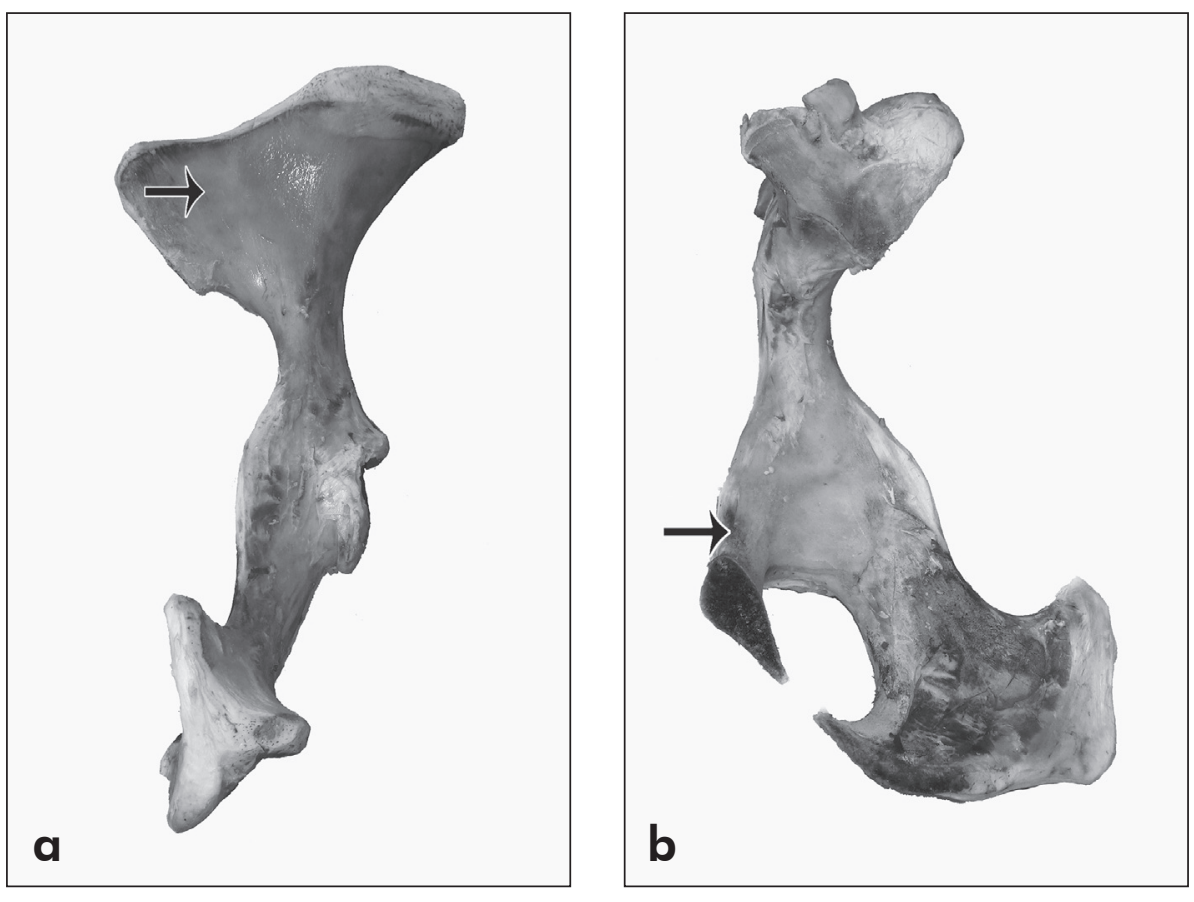
eter $\times 20 \mathrm{~mm}$ long, Sin Implantes, São Paulo, Brazil) adapted to a low speed motor (Beltec LB100, Araraquara, Brazil) under irrigation. The bone sections were taken from a region in which cortical bone was about $1 \mathrm{~mm}$ thick (measured with an orthodontic caliper, Odin, Ortho-pli, Philadelphia, USA). One of the two bone sections taken from each region was used to measure bone mineral density and evaluate primary stability. These samples were immersed in sterile physiological solution and stored by freezing $\left(-20{ }^{\circ} \mathrm{C}\right)$ until the tests were performed. The other section removed from each bone was used for histomorphometric analysis. These samples were immersed in $10 \%$ buffered formalin solution for 2 days for fixation.

\section{Bone mineral density evaluation (BMD)}

The bone mineral content of specimens was measured and divided into areas to obtain bone mineral density by means of central dual-energy X-ray absorptiometry (DEXA) (GE/Lunar Prodigy, Madison, USA), calibrated for small animals. To perform the exam, the bone blocks were thawed at room temperature and were put into plastic boxes $(6 \times 11 \times 4 \mathrm{~cm})$ containing raw rice to simulate soft tissue during irradiation. After this the samples were irradiated by DEXA for 30 seconds. ${ }^{17}$

\section{Histomorphometric evaluation}

After being immersed in $10 \%$ buffered formalin solution for 2 days, the samples were decalcified in Morse solution $^{18}$ (equal parts of $50 \%$ formic acid and 20\% sodium citrate - Vetec Química Fina Ltda., Rio de Janeiro, Brazil) by immersion for 7 days and then embedded in paraffin. Longitudinal sections were cut into $5-\mu \mathrm{m}$ slices and stained with picrosirius for histologic evaluation. Histomorphometric analysis of bone samples was performed using Image J software (National Institute of Mental Health, Bethesda, USA). Digitized photomicrographs (microscope Nikon Eclipse E600, magnification $\times 40$, camera DS-U2, Nikon Corporation, Tokyo, Japan) were taken and analyzed by the same examiner $($ ICC $=0.971)$. The histomorphometric evaluation result was given as a percentage of trabecular bone area (TBA).

\section{Primary stability evaluation}

Primary stability was evaluated by measuring insertion torque (IT) and pull-out strength (PS). Twenty miniscrews (INP ${ }^{\circledR}$, São Paulo, Brazil) $1.4 \mathrm{~mm}$ in diameter and $6 \mathrm{~mm}$ long were inserted into the bone blocks used for BMD evaluation. This was done with the use of a manual placement key connected to a digital torque meter (Lutron TQ-8800, Taipei, Taiwan), to allow the measurement of peak implant placement torque. The values were recorded in Newton centimeter $(\mathrm{Ncm})$. After this, the pull-out test, which consists of extracting the miniscrew from bone at a constant velocity, was performed to evaluate the maximum force required to remove it. ${ }^{19}$ The mechanical test was performed in a universal test machine (Emic DL 2000, São José dos Pinhais, Brazil), using a $500 \mathrm{kgf}$ load cell at a crosshead speed of $0.05 \mathrm{~mm}$ per second ${ }^{19}$ to remove the miniscrew. The maximum pull-out strength was recorded.

\section{Statistical analysis}

The data were evaluated using the Statistical Package for Social Sciences (version 17, SPSS Inc., Chicago, USA). The values obtained were tabulated and submitted to descriptive analysis. The normality and homogeneity of variables were verified by Shapiro-Wilk and Levene's tests. Intergroup comparisons of mean values were performed by the paired T-test at a level of significance of $5 \%$.

\section{Results}

Under light microscopy, the histological sections revealed the presence of trabecular bone with osteocytes and marrow spaces filled with fat marrow. The marrow spaces were larger in Iliac bone. Descriptive statistics and the paired T-test results are shown in Table 1.

Statistical difference was observed for the variables that evaluated bone quality: $\mathrm{BMD}-\mathrm{P}=0.000$; TBA $-\mathrm{P}=0.002$. The difference in trabecular bone density between the iliac and pubic bones is shown in Figure 2. The variables that evaluated primary stability (IT and PS) showed no statistical difference ( $\mathrm{P}=0.071$ and $\mathrm{P}=0.387$, respectively). 
Table 1 - Descriptive analysis and paired T-test comparing the four variables for iliac and pubic bones.

\begin{tabular}{|c|c|c|c|}
\hline & Iliac (mean and SD) & Pubic (mean and SD) & paired T-test \\
\hline $\mathrm{BMD} \mathrm{g} / \mathrm{cm}^{2}$ & $0.13 \quad(0.01)$ & $0.16 \quad(0.00)$ & $P=0.000^{*}$ \\
\hline Trabecular bone density (\%) & $24.23 \quad(6.12)$ & $39.01 \quad(7.95)$ & $P=0.002^{*}$ \\
\hline IT (Ncm) & $7.13(0.75)$ & $6.23 \quad(0.20)$ & $P=0.071$ \\
\hline$P S(N)$ & $203.33(91.11)$ & $164.33(23.07)$ & $P=0.387$ \\
\hline
\end{tabular}

* Indicates statistical significant difference at $\alpha=0.05 \%$
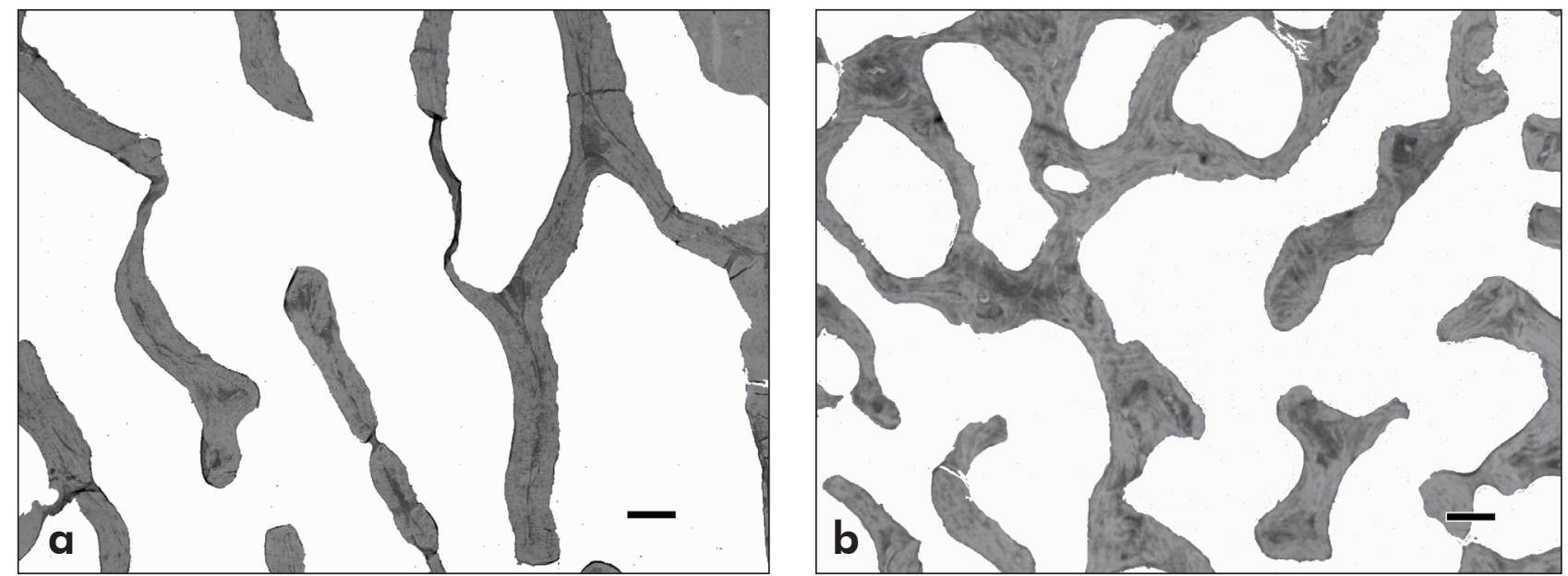

Figure 2 - Micrograph of iliac (a) and pubic (b) bones (picrosirius, 40x, bars $=100 \mu \mathrm{m}$ ). Note that the marrow spaces are larger in iliac bone (a).

\section{Discussion}

Pelvic bone has previously been used in studies with miniscrews. ${ }^{4,20,21,22}$ During exploration of this bone, it was observed that some characteristics such as color, texture and drill resistance differed in its various regions. Pubic bone was darker and more resistant when compared with iliac bone. Therefore, these two regions of the pelvic bone were chosen for this study. The BMD results showed that they are less dense than human jaw bones, as previously related in the literature by Devlin et al. ${ }^{23}$ indicating the following values: maxilla anterior region $=0.55 \mathrm{~g} /$ $\mathrm{cm}^{2}$; maxilla posterior region $=0.31 \mathrm{~g} / \mathrm{cm}^{2}$; mandible $=1.11 \mathrm{~g} / \mathrm{cm}^{2}$; and by Choel et al.,$^{24}$ indicating values for dentate mandible $=0.604 \mathrm{~g} / \mathrm{cm}^{2}$; and edentulous mandible $=0.521 \mathrm{~g} / \mathrm{cm}^{2}$. However, the two cited studies presented a large variation in values for mandibular BMD. Trabecular bone density evaluation, however, showed that the TBA value for pubic bone was similar to the results previously described by Aksoy et al. ${ }^{25}$ for maxilla (= $\left.38.20 \pm 9.65\right)$ and for mandible $(=44.08 \pm 14.97)$. The results of this study showed that the iliac and the pubic bones (of which the pelvis is composed) present different bone qualities: bone mineral density and trabecular bone density. These characteristics, however, had no influence on the primary stability of mini-implants inserted in bone when the cortical was $1 \mathrm{~mm}$ thick.

Mean values for IT ranged from 6.23 to $7.13 \mathrm{Ncm}$, representing adequate primary stability according to Motoyoshi et al., ${ }^{26}$ who stated that these values should range from 5 to $10 \mathrm{Ncm}$.

Pull-out strength values ranged from 164.33 to 203.33 N, being within the range found by Huja et al. ${ }^{19}$ in a study with dog jaws: $134.5 \mathrm{~N}$, for anterior mandible, and $388.3 \mathrm{~N}$ for posterior mandible. Nevertheless, no landmark for adequate pull-out strength value was found in the literature.

A previous study evaluated the influence of BMD on the primary stability of miniscrews and, despite methodological differences, found a similar result. ${ }^{27}$ No correlation was found between BMD, verified 
by cone beam computed tomography, and miniscrew stability, assessed by placement torque. The authors also investigated the influence of cortical bone and found that cortical thickness and cortical BMD were positively correlated with miniscrew stability. ${ }^{27}$ No studies evaluating the influence of TBA on miniscrew stability were found.

Two hypotheses were formulated to explain the results of the present study. The first is that the presence of a cortical thickness of $1 \mathrm{~mm}$ in all of the specimens had an important influence on miniscrew stability, masking the influence of bone mineral density and trabecular density. Cortical thickness has been related to primary stability of miniscrews and implants. ${ }^{5,12,28,29,30}$ However, there is a lack of studies isolating these two factors: bone density and cortical thickness. The second hypothesis is that the difference in bone quality verified statistically may not be clinically relevant. A bigger difference between BMD and TBA values in bones could perhaps reflect differences in mini-implant stability.

Despite the limitations of this in vitro study, it can be inferred that, in clinical practice, a cortical thickness of $1 \mathrm{~mm}$ is sufficient to guarantee the primary stability of miniscrews, as previously sup-

\section{References}

1. Molly L. Bone density and primary stability in implant therapy. Clin Oral Implants Res. 2006 Oct;17 Suppl 2:124-35.

2. Javed F, Romanos GE. The role of primary stability for successful immediate loading of dental implants. A literature review. J Dent. 2010 Aug;38(8):612-20.

3. Gedrange T, Hietschold V, Mai R, Wolf P, Nicklisch M, Harzer W. An evaluation of resonance frequency analysis for the determination of the primary stability of orthodontic palatal implants. A study in human cadavers. Clin Oral Implants Res. 2005 Aug;16(4):425-31.

4. Wilmes B, Rademacher C, Olthoff G, Drescher D. Parameters affecting primary stability of orthodontic mini-implants. J Orofac Orthop. 2006 May;67(3):162-74.

5. Song YY, Cha JY, Hwang CJ. Mechanical characteristics of various orthodontic mini-screws in relation to artificial cortical bone thickness. Angle Orthod. 2007 Nov;77(6):979-85.

6. Trisi P, De Benedittis S, Perfetti G, Berardi D. Primary stability, insertion torque and bone density of cylindric implant ad modum Branemark: Is there a relationship? An in vitro study. Clin Oral Implants Res. 2011Nov;22(5):567-70. posed by Motoyoshi et al., ${ }^{30}$ even when there are variations in BMD and TBA values.

Further research is suggested isolating the cortical effect and increasing the difference in density between different types of bone.

\section{Conclusions}

- Iliac and pubic bones present different BMD and TBA values, the iliac being less dense when considering the two parameters;

- Miniscrew primary stability was not influenced by these differences in bone density.

\section{Acknowledgements}

The authors would like to express their grateful appreciation to the following entities and persons: CAPES (Cordenação de Aperfeiçoamento de Pessoal de Nível Superior) and FAPERJ (Fundação de Amparo à Pesquisa do Estado do Rio de Janeiro) for the financial support provided; INP (Sistema de Implantes Nacionais e de Próteses) for the donation of the miniscrews; Frigorifico Silva for the donation of the bones; doctors Maria Lucia Fleiuss Farias and Laura Maria Carvalho Mendonça for their support during bone mineral density analysis.

7. Freudenthaler JW, Haas R, Bantleon HP. Bicortical titanium screws for critical orthodontic anchorage in the mandible: a preliminary report on clinical applications. Clin Oral Implants Res. 2001 Aug;12(4):358-63.

8. Cheng SJ, Tseng IY, Lee JJ, Kok SH. A prospective study of the risk factors associated with failure of mini-implants used for orthodontic anchorage. Int J Oral Maxillofac Implants. 2004 Jan-Feb;19(1):100-6.

9. Mischkowski RA, Kneuertz P, Florvaag B, Lazar F, Koebke J, Zoller JE. Biomechanical comparison of four different miniscrew types for skeletal anchorage in the mandibulo-maxillary area. Int J Oral Maxillofac Surg. 2008 Oct;37(10):948-54.

10. Melsen B, Costa A. Immediate loading of implants used for orthodontic anchorage. Clin Orthod Res. 2000 Feb;3(1):23-8.

11. Garfinkle JS, Cunningham LL Jr., Beeman CS, Kluemper GT, Hicks EP, Kim MO. Evaluation of orthodontic mini-implant anchorage in premolar extraction therapy in adolescents. Am J Orthod Dentofacial Orthop. 2008 May;133(5):642-53.

12. Merheb J, Van Assche N, Coucke W, Jacobs R, Naert I, Quirynen M. Relationship between cortical bone thickness or computerized tomography-derived bone density values and 
implant stability. Clin Oral Implants Res. 2010 Jun;21(6):6127.

13. Cehreli MC, Kokat AM, Comert A, Akkocaoglu M, Tekdemir I, Akca K. Implant stability and bone density: assessment of correlation in fresh cadavers using conventional and osteotome implant sockets. Clin Oral Implants Res. 2009 Oct;20(10):1163-9.

14. Bergkvist G, Koh KJ, Sahlholm S, Klintstrom E, Lindh C. Bone density at implant sites and its relationship to assessment of bone quality and treatment outcome. Int J Oral Maxillofac Implants. 2010 Mar-Apr;25(2):321-8.

15. Lekholm U, Zarb G. Patient selection and preparation. In: Branemark PI, Zarb G, Albrektsson T, editors. Tissue-integrated prostheses: osseointegration in clinical dentistry. Chicago: Quintessence; 1985. p. 199-209.

16. Carey JJ, Delaney MF, Love TE, Richmond BJ, Cromer BA, Miller PD, et al. DXA-generated Z-scores and T-scores may differ substantially and significantly in young adults. J Clin Densitom. 2007 Oct-Dec;10(4):351-8.

17. Pithon MM, Andrade ACDV, Rodrigues VB, Santos RL. Influence of the immunossuppressant tracolimus (FK-506) on the flexural strength of femur: a study in rats. Rev Bras Ortop. 2010;45(3):286-89.

18. Morse A. Formic acid-sodium citrate decalcification and butyl alcohol dehydration of teeth and bones for sectioning in paraffin J Dent Res. 1945;24(3):11.

19. Huja SS, Litsky AS, Beck FM, Johnson KA, Larsen PE. Pullout strength of monocortical screws placed in the maxillae and mandibles of dogs. Am J Orthod Dentofacial Orthop. 2005 Mar;127(3):307-13.

20. Wawrzinek C, Sommer T, Fischer-Brandies H. Microdamage in cortical bone due to the overtightening of orthodontic microscrews. J Orofac Orthop. 2008 Mar;69(2):121-34.

21. Wilmes B, Su YY, Drescher D. Insertion angle impact on primary stability of orthodontic mini-implants. Angle Orthod. 2008 Nov;78(6):1065-70.
22. Su YY, Wilmes B, Honscheid R, Drescher D. Application of a wireless resonance frequency transducer to assess primary stability of orthodontic mini-implants: an in vitro study in pig ilia. Int J Oral Maxillofac Implants. 2009 JulAug;24(4):647-54.

23. Devlin H, Horner K, Ledgerton D. A comparison of maxillary and mandibular bone mineral densities. J Prosthet Dent. 1998 Mar;79(3):323-7.

24. Choel L, Duboeuf F, Bourgeois D, Briguet A, Lissac M. Trabecular alveolar bone in the human mandible: a dual-energy x-ray absorptiometry study. Oral Surg Oral Med Oral Pathol Oral Radiol Endod. 2003 Mar;95(3):364-70.

25. Aksoy U, Eratalay K, Tozum TF. The possible association among bone density values, resonance frequency measurements, tactile sense, and histomorphometric evaluations of dental implant osteotomy sites: a preliminary study. Implant Dent. 2009 Aug;18(4):316-25.

26. Motoyoshi M, Hirabayashi M, Uemura M, Shimizu N. Recommended placement torque when tightening an orthodontic mini-implant. Clin Oral Implants Res. 2006 Feb;17(1):109-14.

27. Cha JY, Kil JK, Yoon TM, Hwang CJ. Miniscrew stability evaluated with computerized tomography scanning. Am J Orthod Dentofacial Orthop. 2010 Jan;137(1):73-9.

28. Pithon MM, Nojima LI. Evaluation of the primary stability of orthodontic miniscrew in different regions of maxilla and mandible of pigs. Innovations Implant Journal - Biomaterials and Esthetics. 2007;2(4):58-63.

29. Motoyoshi M, Inaba M, Ono A, Ueno S, Shimizu N. The effect of cortical bone thickness on the stability of orthodontic mini-implants and on the stress distribution in surrounding bone. Int J Oral Maxillofac Surg. 2009 Jan;38(1):13-8.

30. Motoyoshi M, Yoshida T, Ono A, Shimizu N. Effect of cortical bone thickness and implant placement torque on stability of orthodontic mini-implants. Int J Oral Maxillofac Implants. 2007 Sep-Oct;22(5):779-84. 